\title{
Pelatihan Pembuatan Media Pembelajaran Berbasis Mobile Menggunakan PowerPoint Bagi Guru-guru SMP, SMK dan SMA Di Kabupaten Cilacap
}

\author{
Isa Bahroni ${ }^{1 *}$, Riyadi Pirwanto ${ }^{2}$, Nur Wahyu Rahadi ${ }^{3}$ \\ ${ }^{1,2}$ Program Studi Teknik Informatika, Negeri Cilacap, Indonesia \\ ${ }^{3}$ Program Studi Teknik Mesin, Universitas Cilacap, Indonesia \\ Email: ${ }^{1}$ isalab21@gmail.com, ${ }^{2}$ adidok_bayu@yahoo.com, ${ }^{3}$ n.wahyu.r08@gmail.com
}

\section{INFORMASI ARTIKEL}

\section{Data artikel:}

Naskah masuk, 2 Agustus 2019

Direvisi, 27 Agustus 2019

Diiterima, 31 Agustus 2019

\section{Kata Kunci:}

Pelatihan,

Belajar Merancang,

Pembelajaran,

Berbasis Android

\begin{abstract}
ABSTRAK
Abstract- E-learning or electronic learning is a concept of learning carried out through electronic media networks. The development of highly advanced technology in the modern era and globalization enables various activities to be carried out quickly and efficiently. The development of technology has a lot of influence on our way of life, one of which is in the field of education with the use of e-learning. One of the developments in the telecommunications sector that is growing rapidly is cellular phones. Java is the standard language for making Android applications. If you have never studied java, you will have difficulty learning android. PowerPoint applications that are part of Microsoft Office are tools that can be manipulated to design a learning application that is quite attractive. Grafting ispring and saktibuider tools on powerpoint then the process of making an android application does not need to think about coding which is quite boring especially for beginners. The learning model will be made easier if every subject teacher can make learning by summarizing the subject book being taught using the Android-based application model. The application can be accessed by students as handbooks that can be read at any time using an Android smartphone, of course this will facilitate students in learning, especially elementary, middle and high school students.
\end{abstract}
Abstrak- E-learning atau electronic learning merupakan konsep pembelajaran yang dilakukan melalui jaringan media elektronik. Perkembangan teknologi yang sangat maju di era modern dan globalisasi memungkinkan berbagai kegiatan dilakukan secara cepat dan efisien. Perkembangan teknologi sudah banyak memberi pengaruh terhadap cara hidup kita, salah satunya adalah dalam bidang pendidikan dengan penggunaan e-learning. Salah satu perkembangan dibidang telekomunikasi yang berkembang pesat adalah telepon seluler (ponsel). Smart phone memiliki berbagai fungsi seperti multimedia, video streaming, transfer data. Java adalah bahasa yang standar untuk pembuatan aplikasi Android. Jika anda tidak pernah belajar java, anda akan mengalami kesulitan belajar android. Aplikasi PowerPoint yang merupakan bagian 
dari Microsoft Office adalah tools yang dapat dimanipulasi untuk merancang sebuah aplikasi pembelajaran yang cukup atraktif. Mencangkokkan tools ispring dan Saktibuider pada powerpoint maka proses pembuatan aplikasi android tidak perlu memikirkan coding yang cukup membosankan apalagi bagi pemula. Model pembelajaran akan dipermudah jika setiap guru mapel dapat membuat pembelajaran dengan meringkes buku mapel yang diajarkan dibuat menggunakan model aplikasi berbasis android. Aplikasi tersebut dapat diakses oleh murid kelas sebagai hand book yang setiap saat dapat dibaca menggunakan smartphone android sudah barang tentu hal ini akan mempermudah siswa dalam belajar, khususnya siswa SD, SMP dan SMA.

\section{Korespondensi:}

\section{Isa Bahroni}

Program Studi Teknik Informatika, Politeknik Negeri Cilacap

Jl. Dr. Soetomo No.1 Karangcengis, Sidakarya Cilacap, Indonesia

\section{PENDAHULUAN}

E-learning atau electronic learning merupakan sebuah konsep pembelajaran yang dilakukan melalui jaringan media elektronik. Perkembangan teknologi yang sangat maju di era modern dan globalisasi menuntut berbagai kegiatan dilakukan secara cepat dan efisien. Perkembangan teknologi sudah sangat banyak memberi pengaruh terhadap cara hidup kita, salah satunya adalah dalam bidang pendidikan seperti metode e-learning, proses kegiatan pembelajaran di sekolah maupun perguruan tinggi (Mulia \& Suwarno, 2016). Seiring dengan perkembangan teknologi informasi dan tuntutan globalisasi pendidikan serta pembelajaran jarak jauh, berbagai konsep telah dikembangkan untuk menggantikan metode pembelajaran tradisional, salah satunya adalah metode e-learning (Wiganda, 2014). Elearning dapat digunakan sebagai alternatif atas permasalahan dalam bidang pendidikan, baik sebagai tambahan, pelengkap maupun pengganti atas kegiatan pembelajaran yang sudah ada (Somatanaya \& Herawati, 2017). Model e-learning merupakan sebuah inovasi yang mempunyai kontribusi sangat besar terhadap perubahan proses pembelajaran, dimana proses belajar tidak lagi hanya mendengarkan uraian materi dari guru tetapi siswa juga melakukan aktivitas lain seperti mengamati, melakukan, mendemonstrasikan dan lain-lain. Materi bahan ajar dapat divisualisasikan dalam berbagai format dan bentuk yang lebih dinamis dan interaktif sehingga learner atau murid akan termotivasi untuk terlibat lebih jauh dalam proses pembelajaran tersebut.

Salah satu perkembangan dibidang telekomunikasi yang berkembang pesat adalah telepon seluler (ponsel). Mulai dari ponsel yang hanya bisa menerima telepon dan pesan singkat hingga "ponsel pintar" (smart phone) yang memiliki berbagai fungsi seperti multimedia, video streaming, transfer data. Berbagai operating system mobile bermunculan, salah satunya yang cukup dikenal yaitu Android. Pemilihan telepon seluler platform berbasis Android untuk salah satu pengembangan aplikasi selain bersifat open source dan lebih mudah dalam pengoperasiannya, sifat dari telepon seluler yang fleksibel menjadi juga salah satu alasannya.

Salah satu bentuk pemanfaatan yang perlu kita ambil adalah dalam mengakses informasi edukatif, alasannya karena perkembangan ini juga seiring dengan perkembangan sistem informasi akademik seperti portal Akademik, digital library dan perkembangan dunia 
internet yang kini menyediakan ribuan hingga jutaan link dan Laman web (situs) yang memuat hal -hal yang bersifat pendidikan seperti riset, ejournal, ebook, ensiklopedi, digital library yang dapat diakses secara online. Aktivitas ini merupakan salah satu bentuk komunikasi dengan menggunakan smartphone android. Android dimanfaatkan sebagai media oleh mahasiswa untuk mengakses informasi edukasi.

Java adalah bahasa pemrograman yang digunakan untuk development android apps secara native. Java adalah bahasa yang standar untuk pembuatan aplikasi Android. Jika anda tidak pernah belajar java, namun tiba-tiba coding java di android, anda akan mengalami kesulitan. Konsep seperti Class, Package, access modifier (public/prifat) dan konsep lain harus anda pelajari dulu. Satu hal lagi, Java juga menganut konsep Pemrograman Berorientasi Object (OOP). Kebiasaan seseorang dalam belajar Android, langsung saja download source code istilahnya Copy Paste dan programnnya jalan, namun anda akan kesulitan ketika membuat program android dari awal dan akan sulit memahaminya struktur coding nya.

Mensikapi informasi diatas harus dicari strategi baru, agar dengan tools yang telah tersedia dan hampir semua pendidik di tingkat SLTA dapat dengan mudah untuk mengoperasikan. Memanipulasi sebagai alat bantu untuk merancang sebuah materi pembelajaran berbasis android yang tidak harus mahir membuat coding bahkan tidak tahu sama sekali, yang hasilnya dapat diakses melalui media smartphone. Terutama untuk semua kalangan guru mapel agar bisa membuat materi pelajaran yang dikemas dalam sebuah aplikasi berbasis android, sehingga semua siswa didiknya dapat mengakses dengan mudah sebagai bahan belajar dengan praktis bahkan sambil bermain.

Aplikasi power point yang merupakan bagian dari Microsoft Office adalah tools yang dapat dimanipulasi untuk merancang sebuah aplikasi pembelajaran yang cukup atraktif. Mencangkokkan tools ispring pada powerpoint dan di dukung dengan software buatan local dengan label saktibuider maka proses pembuatan aplikasi android tidak perlu merancang sebuah coding yang cukup membosankan apalagi bagi pemula.

Proses pembelajaran akan dipermudah jika setiap guru mapel dapat membuat model pembelajaran dengan meringkes buku mapel yang diajarkan kepada muridnya, dibuat menggunakan model aplikasi berbasis android. Aplikasi tersebut selanjutnya dapat diakses oleh murid kelas sebagai hand book yang setiap saat dapat dibaca menggunakan smartphone android sudah barang tentu hal ini akan mempermudah siswa dalam belajar.

\section{METODE PELAKSANAAN}

\subsection{Metode Pelatihan}

Pelaksanaan Kegiatan Pengabdian Kepada Masyarakat ini adalah pelatihan membuat media pembelajaran E-learning atau electronic learning berbasis mobile menggunakan aplikasi PowerPoint, pelaksanaan kegiatan berupa workshop pelatihan dari mulai install software sakti builder yang di buat oleh tim MUGI Purwokerto sampai pelatihan membuat materi pembelajaran sesuai dengan masing masing mapel peserta kegiatan, diantaranya sebagai berikut:

a) Pelatihan dilakukan dengan metode praktek di kelas dengan menggunakan laptop, masing-masing peserta diwajibkan membawa laptop sendiri-sendiri.

b) Pelatihan membuat materi pembelajaran $e$ learning menggunakan powerpoint, install tools sakti bulder yang akan dicangkokkan ke software aplikasi powerpoint.

c) Proses cara membuat apk dan cara upload ke google play store agar siswa didiknya dapat men-download aplikasi yang telah dibuat.

\subsection{Waktu Pelaksanaan}

Pelaksanaan kegiatan bertempat di aula SMK Negeri 1 Cilacap diikuti oleh 50 peserta dengan waktu pelaksanaan dari jam 08.00 18.00 WIB. 


\subsection{Peserta Workshop}

Peserta workshop yang mengikuti kegiatan ini berasal dari beberapa guru dari tingkat TK, SD, SMP, SMA dan SMK. Seperti pada Tabel 1.

Tabel 1. Data Peserta Workshop

\begin{tabular}{llc}
\hline No & \multicolumn{1}{c}{ Peserta Workshop } & Jumlah \\
\hline 1 & Guru TK & 8 \\
2 & Guru SD & 10 \\
3 & Guru SMP & 12 \\
4 & Guru SMA dan SMK & 20 \\
\hline & Jumlah : & 50
\end{tabular}

\section{HASIL DAN PEMBAHASAN}

\subsection{Pelaksanaan Kegiatan}

Para peserta workshop yang diikuti oleh guru-guru SMP, SMA dan SMK bahkan ada beberapa guru yang dari SD dan Taman Kanak-Kanak karena para guru tersebut sangat ingin sekali bisa belajar dan mengetahui cara membuat metode pembelajaran berbasis android. Beberapa peserta dibagi menjadi beberapa grup sesuai dengan mata pelajaran yang di ampu disekolahnya masing-masing. Kolaborasi peserta workshop menghasilkan pembelajaran berupa latihan soal-soal UN untuk SMP yang terdiri dari mata pelajaran Bahasa Indonesia, Matematika, IPA dan Bahasa Inggris.

Adapun pelaksanaan kegiatan workshop seperti Gambar 1.

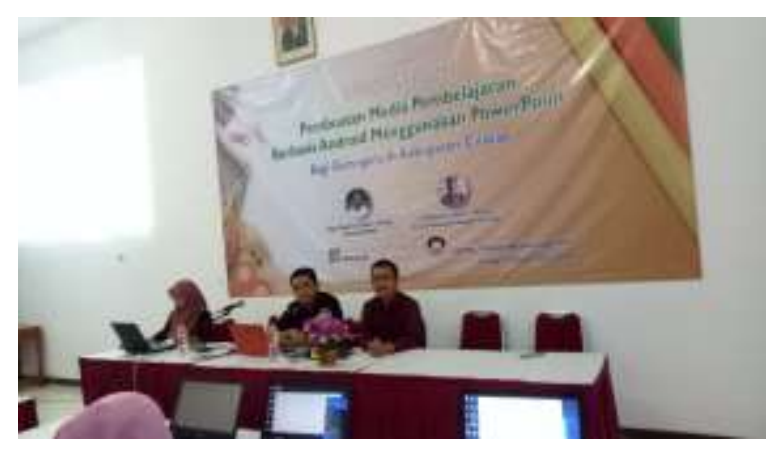

Gambar 1. Pemateri workshop e-learning

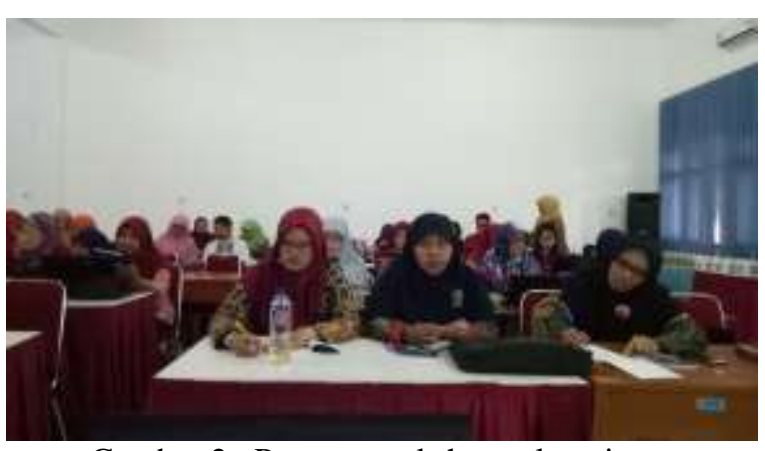

Gambar 2. Peserta workshop e-learning

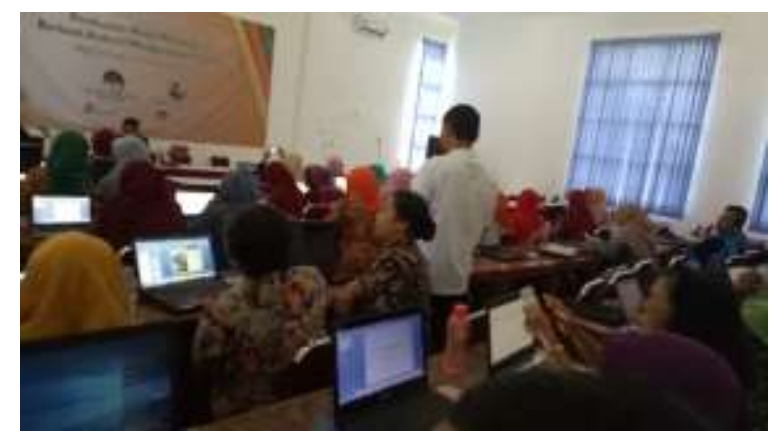

Gambar 3. Peserta workshop Instal Aplikasi Saktibuider

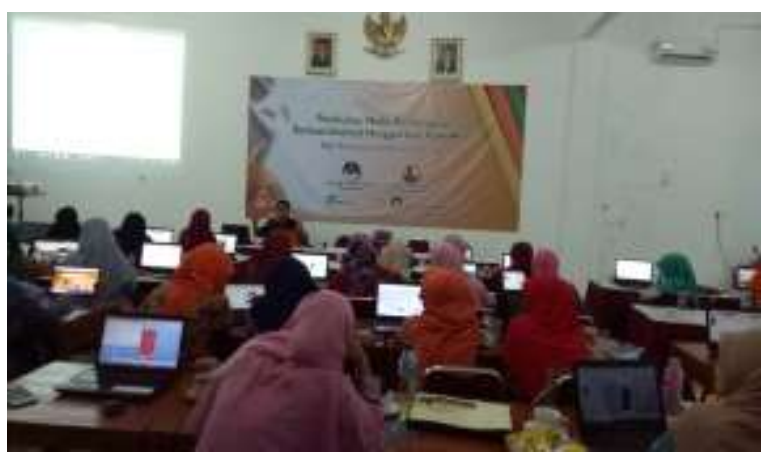

Gambar 4. Peserta Pembuatan Model Pembelajaran Sesuai Mapel Masing-Masing

Tampilan menu materi sebagai pilihan yang akan dikerjakan oleh siswa dalam belajar menggunakan media smart phone. Tampilan akan dibagi dalam beberapa sub menu sesuai dengan materi mata pelajaran, seperti pada menu layar smart phone diantaranya soal latihan bahasa indonesia, soal latihan matematika, soal latihan IPA dan soal bahasa inggris.

\subsection{Hasil Aplikasi Peserta Workshop}

a) Latihan soal-soal Bahasa Indonesia

Mengoperasikan aplikasi yang telah dikumpulkan dari beberapa peserta dimulai 
dengan tampilan menu pada aplikasi soal-soal UN 2019. Seperti pada Gambar 5.

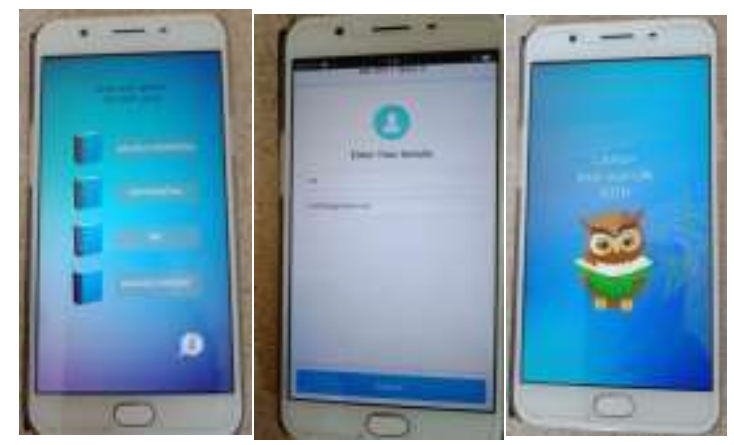

Gambar 5. Menu Utama Soal BHS Indonesia

b) Latihan Soal-Soal UN Matematika

Menu tampilan soal - soal maplel matematika. Dapat dilihat pada Gambar 6.

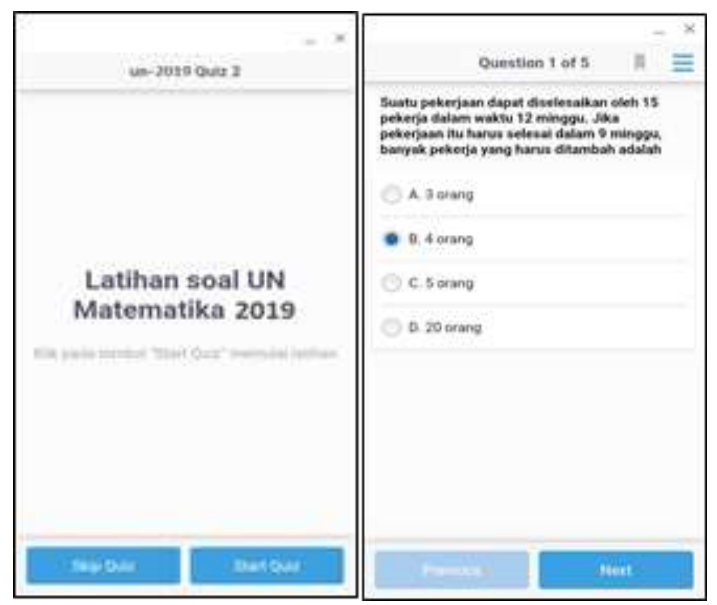

Gambar 6. Menu Utama Soal Matematika

\section{c) Latihan Soal-Soal UN IPA}

Menu tampilan soal - soal maplel Ilmu Pengetahuan Alam. Dapat dilihat tampilan pada Gambar 7.

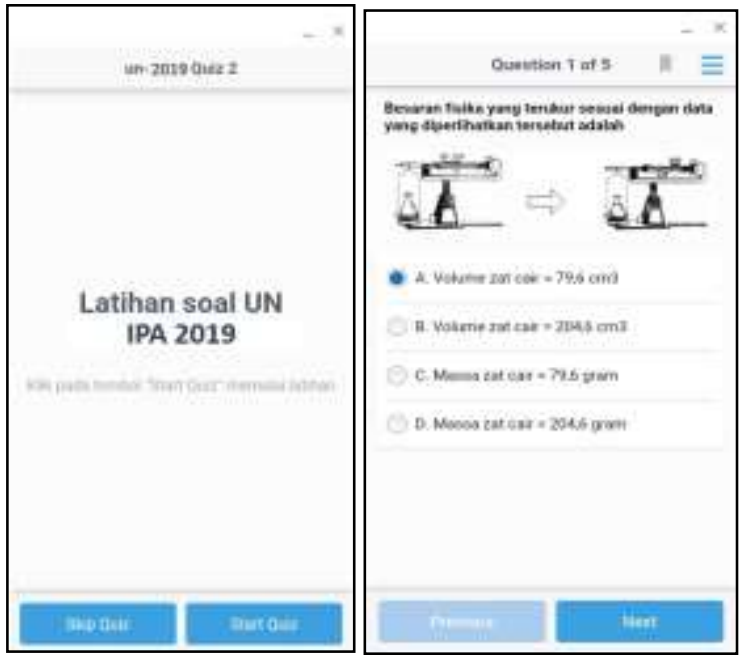

Gambar 7. Menu Utama Soal UN IPA

d) Latihan Soal-Soal UN Bahasa Inggris

Menu tampilan soal - soal maplel matematika. Dapat dilihat pada Gambar 8.

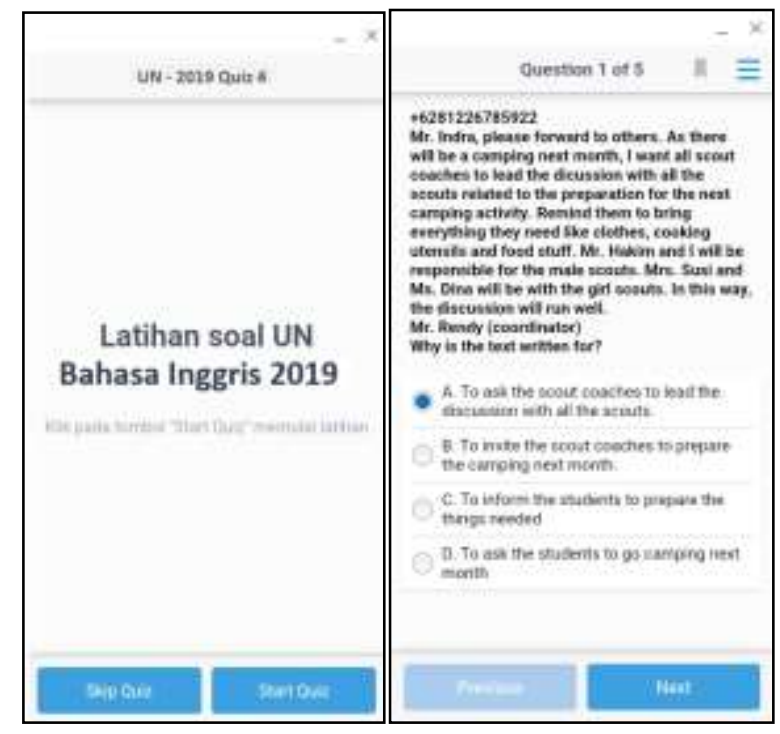

Gambar 8. Menu Utama Soal UN BHS Inggris

\section{KESIMPULAN}

Kemajuan bidang teknologi informatika mendorong semua sektor dapat dikerjakan dengan cepat mudah dan akurat. Bidang pendidikan salah satu sektor utama yang banyak menggunakan dan memanfaatkan teknologi tersebut. Kemudahan selalu menuntut untuk kita berkreasi dengan hadirnya teknologi, dalam hal ini terutama yang mencakup bidang proses pembelajaran kepada 
siswa-siswi agar dengan mudah dapat di menjangkau dan memanfaatkan dengan baik. Pelatihan workshop membuat media pembelajaran berbasis mobile dengan menggunakan media PowerPoint yang di cangkok dengan aplikasi saktibuider.com sangat cocok digunakan dan diajarkan sebagai bahan pelatihan bagi guru-guru yang awam dengan proses pemrograman karena berbasis Android.

Menggunakan Aplikasi android cenderung berfikir betapa susahnya harus belajar coding tetapi dengan adanya aplikasi saktibuider.com semua akan dipermudah karena proses perencanaan dan perancangan tidak berkutit dengan coding bahkan hanya dibantu dengan aplikasi PowerPoint yang merupakan software microsoft office yang hampir semua guru rata-rata dapat mengoperasikan denganbaik tanpa banyak kendala. Sehingga workshop berjalan dengan baik bahkan banyak peserta yang menginginkan untuk diadakan kembali untuk memperkuat dan memperlancar proses pembuatan materi pembelajaran.

\section{UCAPAN TERIMA KASIH}

Terimakasih disampaiakan kepada Politeknik Negeri Cilacap atas pendanaan kegiatan PKM yang telah dilaksanakan dan kepada mitra kegiatan pengabdian yaitu SMK Negeri 1 Cilacap dan MUGI Purwokerto.

\section{DAFTAR PUSTAKA}

Mulia, D. S., \& Suwarno. (2016). Ptk (Penelitian Tindakan Kelas) Dengan
Pembelajaran Berbasis Kearifan Lokal Dan Penulisan Artikel Ilmiah Di Sd Negeri Kalisube, Banyumas. Khazanah Pendidikan Jurnal Ilmiah Kependidikan, IX(2), 11. Retrieved from http://jurnalnasional.ump.ac.id/index.php/ khazanah/article/view/1062/983

Somatanaya, A. A. G., \& Herawati, L. (2017). Pelatihan Penelitian Tindakan Kelas ( Ptk ) Bagi Peningkatan Karier Guru-Guru Sekolah Dasar. Jurnal Siliwangi, 3(1), 169-175.

Wiganda, S. (2014). Pelatihan Penelitian Tindakan Kelas Bagi Guru-Guru SeJakarta Timur. Sarwahita, 11(1), 1. https://doi.org/10.21009/sarwahita.111.01

Hakim, A.B., (2016). Efektifitas Penggunaan E-Learning Moodle, Google Classroom Dan Edmodo. I-STATEMENT: Information System and Technology Management (e-Journal), 2(1).

Kosasi, Sandy. (2015). Perancangan E-learning Untuk Meningkatkan Motivasi Belajar Guru dan Siswa. Prosiding Seminar Nasional Pendidikan Teknik Informatika (SENAPATI 2015). Sigaraia - Bali, 12 September 2015.

Purwandani, Indah. (2016). Pengembangan Elearning Berbasis Claroline untuk Pembelajaran PTIK. Prosiding KNIT 2 Vol 2 No 12016.

Wijaya M. 2012. Pengembangan model pembelajaran e-learning berbasis web dengan prinsip e-Pedagogy dalam meningkatkan hasil belajar. Artikel. Jurnal Pendidikan Penabur. No. 19/Tahun ke11/Desember 2012. 